\title{
Unpacking the Pacific Urban Agenda: Resilience Challenges and Opportunities
}

\author{
Gabriel Luke Kiddle ${ }^{1}$, Darryn McEvoy ${ }^{2, *}$ (D), David Mitchell ${ }^{3}$, Paul Jones ${ }^{4}$ and \\ Sarah Mecartney ${ }^{5}$ \\ 1 School of Geography, Environment and Earth Sciences, Victoria University of Wellington, \\ Wellington 6140, New Zealand; lukekiddle@gmail.com \\ 2 School of Engineering, RMIT University, Melbourne 3001, Australia \\ 3 School of Science, RMIT University, Melbourne 3001, Australia; david.mitchell@rmit.edu.au \\ 4 School of Architecture, Design and Planning, University of Sydney, Sydney 2006, Australia; \\ paul.r.jones@sydney.edu.au \\ 5 Independent consultant, Kabul 999087, Afghan; sarah_mecartney@yahoo.com \\ * Correspondence: darryn.mcevoy@rmit.edu.au
}

Received: 6 September 2017; Accepted: 14 October 2017; Published: 23 October 2017

\begin{abstract}
Pacific Island Countries (PICs) are often cited as being the most vulnerable to the future impacts of a changing climate. Furthermore, being located in the 'Pacific Rim of Fire', PICs have long been exposed to the impacts of a range of natural and climate-related extreme events-such as earthquakes and cyclones-and are considered to be amongst the most vulnerable countries to natural disasters. The physical vulnerability of Pacific towns and cities is further exaggerated by development deficits, geographical isolation, weak governance, and complex issues of land tenure. This paper, based on substantive project experience in the Pacific region by each of the authors, reviews the resilience challenges facing Melanesian cities in the context of rapid urbanization and global environmental change. It then sets this in the context of the global 'New Urban Agenda' which was launched at Habitat III in Quito at the end of 2016, setting out the critical implementation challenges and opportunities for enhancing urban resilience in the Pacific.
\end{abstract}

Keywords: urbanization; climate impacts; governance; urban resilience; Pacific

\section{Introduction}

The majority of Pacific Island Countries (PICs) are rapidly urbanizing (Table 1), with the most dramatic urban population shifts occurring in Melanesia (as host to the major urban centers in the region, this paper addresses the Pacific Urban Agenda predominantly from the Melanesian urbanization context). At current urbanization rates, for example, the urban populations of Papua New Guinea (PNG), Solomon Islands, and Vanuatu are expected to double in 25, 17 and 16 years respectively [1] (p. 70). As of 2015, Melanesia contained approximately $89 \%$ of the total Pacific regional population, as well as the largest population of urban dwellers; some 1.8 million people [2] (p. 12). PICs are judged to be ill-prepared to manage this rapid rate of urban growth in a sustainable manner. As Keen and Barbara noted: "throughout the Pacific islands, urban planning and management remain largely neglected" [4] (p. 1). This has evolved despite many years of efforts by international and regional agencies to galvanize attention and action to better manage urban growth in the Pacific. 
Table 1. Percentage urban in 2014 and projected annual average rate of change of urban population in selected PICs from 2010-2015 [3].

\begin{tabular}{ccc}
\hline Region & Percentage Urban (2014) & $\begin{array}{c}\text { Average Annual \% Rate of Change of the } \\
\text { Urban Population (Projection 2010-2015) }\end{array}$ \\
\hline World & 54 & 2.05 \\
Melanesia & 19 & 2.14 \\
Micronesia & 67 & 1.09 \\
Polynesia & 43 & 0.55 \\
Fiji & 54 & 1.45 \\
Papua New Guinea & 13 & 2.12 \\
Solomon Islands & 22 & 4.25 \\
Vanuatu & 26 & 3.42 \\
\hline
\end{tabular}

The impacts of urbanization are further exaggerated by the presence of a range of natural hazards in the region. Recent calamitous disasters have resulted in deaths, significant economic losses, and social disruption in urban areas, for example the Honiara floods in Solomon Islands in 2014 and Tropical Cyclone Pam in Vanuatu in 2015. A changing climate will further compound urban resilience challenges in the years and decades to come, and building climate resilience therefore needs to be complementary to better managing urban growth in the region.

Local exposure to hazards is already an issue for many urban dwellers. A key reason for this is that large proportions of urban areas are built upon marginal lands such as riverbanks, floodplains, accretion lands, and on low-lying atolls [5]. The vulnerability of PIC urban areas to climate-related impacts is also extremely high due to poor quality housing and deficits in critical infrastructure (sensitivity) as well as a lack of institutional capacity as expressed by weaknesses in governance, political decision making, and land use planning (adaptive capacity). Furthermore, land in urban and peri-urban areas exists under a range of tenure categories including freehold, State, and customary land. The associated land tenure systems have greatly influenced the form and shape of urban development in the Pacific, including urban development expanding beyond existing municipal boundaries onto customary land. In a region dominated by customary land, inherent complexities exist where these traditional forms of land tenure intersect with more formal, introduced systems of tenure [6]. This can lead to increased tensions over land, and improvements to land governance are needed to meet urban resilience objectives.

In response to these multi-faceted challenges, regional stakeholders gathered in Nadi, Fiji, in 2015 to discuss the management of urbanization in the Pacific. The 2015 Pacific Urban Forum, building on earlier forums held in 2003, 2007, and 2011, aimed to develop a new urban agenda for the Pacific. This outcome was to be a regional input to the United Nations Conference on Housing and Sustainable Development (Habitat III) in Quito, Ecuador, in October 2016 which saw the endorsement of a global 'New Urban Agenda'.

\section{Context}

This paper reviews the key resolutions emerging from the Pacific Urban Forum through an analytical 'urban resilience' lens-that is, understanding resilience as the ability of an urban system and its sub-components to withstand, or recover in a timely manner, from shocks and stresses. These can be either external or internal in nature and relate both to human drivers of change (such as urbanization pressures) or the impact of natural and climate-related hazards. The resilience approach taken in this paper recognizes the need to consider multiple drivers in a holistic manner (climate change adaptation, disaster risk reduction, and development issues are agendas that have typically been addressed by discrete communities of practice in the past).

The first section of the paper introduces the Pacific Urban Agenda to set out the necessary policy context for the analysis. It then describes the key resilience challenges for the Pacific in terms of the dominant drivers of change (with a particular focus on rapid urbanization and climate change) 
as well as highlighting the region's unique resilience characteristics; structured according to society and culture, tenure security, natural environment and socio-ecological relationships, and economic categories. These categories allow the resilience characteristics to be mapped to the resolutions that are set out in the Pacific Urban Agenda.

The paper then relates climate resilient urban development in the Pacific to the global 'New Urban Agenda' as adopted at Habitat III in 2016, identifying the key synergies and differences between this new international initiative and the Pacific Urban Agenda. The paper then concludes by highlighting the challenges and opportunities-in terms of spatial planning, land governance, partnership working, and integrated urban resilience action plans-for Pacific towns and cities to fully embrace and respond to the global New Urban Agenda.

\section{The Regional Framework: The Pacific Urban Agenda}

The Pacific Urban Agenda was first initiated in 2003 and subsequently adopted by the United Nations Economic and Social Commission for Asia and the Pacific (UNESCAP) in 2004. It was then integrated into the Pacific Plan in 2005, a key regional initiative of the Pacific Islands Forum Secretariat (PIFS) with additional coordination support from the Pacific Community (SPC). In 2007, a second Pacific Urban Forum was facilitated by the UNESCAP Pacific office in collaboration with UN-Habitat, the Commonwealth Local Government Forum (CLGF), and PIFS. Later in 2007, the outcomes were refined into a Regional Action Framework supported by UN-Habitat, UNESCAP, PIFS, SPC, and CLGF [7] (p. 1). This framework was given additional endorsement at a subsequent 2011 Pacific Urban Forum.

Despite the framework being in place-and UN-Habitat, UNESCAP, and CLGF active as lead agencies-progress on the Pacific Urban Agenda has been inconsistent and has generally lacked traction. Both the PIFS and SPC have not been closely involved in implementation and coordination, citing technical and human capacity constraints [7] (p. 3). The region's development partners have also not come on board to fully elevate the urban sector and make explicit reference to the Pacific Urban Agenda. In addition, only some PICs—such as PNG, Fiji, and Samoa-have prioritized urban issues using the Pacific Urban Agenda framework. In short, issues associated with the Pacific Urban Agenda have continued to be largely side-lined in the region in the absence of a regional 'coalition of the willing' (ibid).

The 2015 Pacific Urban Forum aimed to develop a new Pacific Urban Agenda ahead of Habitat III that would generate greater traction and support from regional agencies, development partners, and individual PICs. Four key recommendations were endorsed in the official Pacific Urban Forum outcomes document and which form the new Pacific Urban Agenda: (i) social equity is to be enhanced; (ii) environment, resilience and urbanization are more comprehensively addressed; (iii) the urban economy is to be harnessed; and (iv) urban governance is to be strengthened [1] (pp. 1-2).

The first of these recommendations recognized the considerable growth of squatter and informal settlements in the Pacific, as well as the acute need for improved water, sanitation, and hygiene services (WASH) in these areas. Recent estimates, for example, suggest that in excess of one million urban dwellers are living in Pacific squatter and informal settlements [8]. These areas are characterised by under-servicing, overcrowding, low quality dwellings, complexities with land tenure, and locations in sensitive locations. Considerable further growth in informal and squatter settlements across the Pacific is expected [9] (p. 5).

The second recommendation addressed a combination of environment, resilience, and urbanization issues, although the overriding focus is on responding to climate change through comprehensive urban vulnerability assessments and associated adaptation planning. Official documentation has previously referenced the importance of climate risk planning, preparedness, response and recovery planning, improving the resilience of urban infrastructure, adequately enforcing laws and regulations, reducing the carbon footprint of urban areas, improving water and waste management, and strengthening the enabling environment, and generally building 
capacity to do all of the above [1] (pp. 8-9). It is also noteworthy that climate vulnerability assessments have been carried out for the Melanesian cities of Honiara, Port Vila, Suva and Port Moresby in recent years as part of the UN-Habitat 'Cities and Climate Change Initiative'. Progressing this agenda, a comprehensive urban resilience and climate action plan for Honiara (the first city-wide action plan in the Pacific) has recently been endorsed by city and national Government and was formally launched early in 2017 [10].

The third key recommendation recognized the importance of urban areas to the economies of PICs. For example, the Pacific Urban Agenda highlighted that well-managed urbanization and improved economic growth are closely linked [1] (p. 6)-reflecting increased global awareness that well managed urbanization and economic growth are positively correlated. The importance of the informal sector for urban livelihoods in the Pacific was also noted: "there should be increased acknowledgement of the influence and contribution of the informal sector to the national and urban economy including sustaining livelihoods" (ibid, p. 9). PNG in 2011, for example, adopted a national informal economy policy so as to both recognize its importance as well as stimulate informal sector activity [11].

An element of the fourth priority of the new Pacific Urban Agenda is recognition of the importance of urban land governance through policy development, supportive legislative frameworks and capacity building. While recognizing the complexities of dual, often intersecting, land tenure systems in the Pacific, and the increasing pressure upon customary systems, the call for action specified the importance of developing and implementing national urban policies which can act to coordinate the work of different sectors and tiers of government, allocate resources effectively, and establish incentives for sustainable practices [1] (p. 10). The call also referenced: (i) continued work to fill policy and legislative gaps; (ii) capacity building across national and local government including land professionals, policy-makers, and political leaders alike; and (iii) multi-stakeholder partnerships to produce innovative and scalable solutions and appropriate financing mechanisms to address urban challenges (ibid, pp. 10-11).

\section{Resilience Shocks and Stresses}

\subsection{Rapid Urbanisation and the Growth of Informal and Squatter Settlements}

Pacific urbanization trends are unique and have been shaped by a number of features. These include the long-lasting influence of the colonial powers who first germinated the growth of many Pacific towns in the 1800s, the relatively recent impact of increasing rural-to-urban migration, and the subsequent rise of squatter and informal settlements. The collective result is that urbanization conditions and management approaches are characterised by: (i) a diversity in social, cultural, ethnic, linguistic, political, economic, and environmental settings that differentiate the three sub-regional groupings of Melanesia, Micronesia, and Polynesia; (ii) the scale and intensity of shocks and stresses that are undermining urban resilience-such as climate change impacts, informal and squatter settlements, urban poverty and service and infrastructure deficiencies; and (iii) a lack of prioritization for urban issues on Pacific town, city, and national development agendas.

Urban population growth is being driven by a combination of natural population growth, migration and reclassification [12]. In many urban areas, natural population growth is the largest of these components although contemporary rural-urban migration is an increasing driver (ibid). This is a consequence of a combination of 'push' factors such as under-employment, conflict, rural poverty, and poor agricultural and local environmental conditions and 'pull' factors as people seek improved schooling, better employment prospects, access to health services and the 'bright lights of the city' [13]. However, migration typically manifests itself as unplanned informal and squatter settlements on unsuitable or hazard-prone land (ibid). Associated problems include poor quality housing, inadequate basic infrastructure, and a lack of formal tenure rights. Overall, urbanization remains both challenging and problematic. 
Challenges with informal and squatter settlements can manifest as evictions, physical insecurity, and discrimination; particularly affecting the more vulnerable and marginalized residents (for example, children, elderly, women and people with disabilities). The way a household transitions from an informal occupancy of land to 'formal settlement' has a major influence on their resilience [2]. Therefore, understanding how the poor and vulnerable in informal and squatter settlements cope is critical in developing responses such as upgrading settlements and integrating the poor into resilient cities [14]. Consideration of this approach has been taken by UN-Habitat's Participatory Slum Upgrading Programme operating in Fiji, PNG, and Solomon Islands. In recent times, some PICs have also taken steps to recognize informal and de facto tenure in these settlements and provide improved basic infrastructure and services for well-established communities-for example, Fiji was one of the first PICs to recognize the rights of informal settlers and extend services to them [15].

In most PICs, and especially Melanesia, the increasing growth of the urban population and informal and squatter settlements, coupled with limited capacity of the land sector, have placed pressure on both formal and customary land tenure systems. As May noted [16], disputes over land boundaries were a common and continuing source of conflict in pre-colonial societies. However, the effects of immigration, internal migration, and rapid urbanization have created new arenas for contestation and negotiation over land, with rural-urban migration elevating issues of the rights of absent claimants to customary land for example.

\subsection{Natural Hazards, and Current and Future Climate}

PICs have historically been highly exposed to natural hazards such as earthquakes and tsunamis. Their geographical location in the Pacific Ocean, covering a third of the Earth's surface, also means that they are already affected by large-scale climate features which influence each country's climate variability [17]. The El Niño-Southern Oscillation (ENSO)—which consists of El Niño, La Niña, and neutral cycles-is the dominant cause of variability on a year by year basis and, due to the sheer scale of the Pacific Ocean, impacts PICs in different ways. For example, El Niño typically brings dry and La Niña wet conditions to the Melanesian countries, although this is the opposite for countries in other parts of the Pacific such as Tuvalu and Kiribati. These 'natural' cycles of the regional climate system are important influences on extreme events such as drought, flooding, tropical cyclones, sea level, and coral bleaching events.

As well as annual variability, the Pacific climate also varies decade by decade and this pattern has been linked to the ENSO-like events (ibid). Other large-scale influences include the South Pacific Convergence Zone (SPCZ), the West Pacific Monsoon (WPM), and the Intertropical Convergence Zone (ICZ). It is clear therefore that PICs are already influenced by a complex mix of large-scale climate systems before considering future climate change impacts. The projected changes to key climatic variables are now summarized from the seminal research outputs from the Pacific-Australian Climate Change Science (2009-2012) and Adaptation Planning Programs (2012-2014) [17].

Temperature: Records show that not only have there been more hot days in recent years (the past decade has been the hottest on record) these hot days are also getting hotter. That is, there have been increases in both frequency and magnitude. Further increases to average temperature are projected to continue into the future. Whilst extreme heat is of most direct concern to the health and well-being of human beings, longer term changes to average temperatures will also impact the natural environment through, for example, coral bleaching, additional stresses on ecosystem functioning, changes to growing seasons, and the distribution of fauna and flora. It is also important to note that whilst temperatures near the equator are relatively constant throughout the year, seasonal variations increase with distance from the equator.

Rainfall: In contrast to relatively stable temperature regimes, rainfall is considerably more variable across the Pacific, both month to month and year to year. This variability makes it difficult to detect trends in rainfall, although one notable trend in the past 30 years is that the south-west has become wetter and the central Pacific drier (although this is a consequence of a south-westward shift 
in the SPCZ rather than being due to climate change). Overall, rainfall is projected to increase in many locations in the Pacific, and extreme events are expected to increase in frequency and intensity, however differences between climate models remain and there is continuing uncertainty about future rainfall. It is therefore advised that a range of different 'futures' are considered for adaptation planning. Drought will continue to be strongly influenced by ENSO but will be exaggerated by increasing urban demands.

Sea level: varies across the Pacific by up to $1 \mathrm{~m}$ and can also vary year to year by up to $20 \mathrm{~cm}$. Projections suggest rises of between $0.26 \mathrm{~m}$ and $0.82 \mathrm{~m}$ depending on the emissions scenario. Whilst this will have direct consequences for low-lying atoll islands, the larger Melanesian islands will still be exposed to loss of land, heightened risk of storm surge, and coastal erosion. Of particular concern is the increased risk of salinization of fresh groundwater, which is a critical water resource for PICs.

Tropical cyclones: are influenced by ENSO with most cyclone activity in the South Pacific occurring between November and April. Due to scale issues, future cyclone activity is not easily measured, although it is projected that there may be less cyclones though these may be more severe and have more potential for damage.

\section{Resilience Characteristics in the Pacific}

\subsection{Society and Culture}

In the Pacific, the role of communities in preparing for and responding to disasters and traditional social and kinship networks are key factors of resilience capacity. The success of preparedness and recovery efforts is reliant on residents' ability to anticipate risk, engage with authorities and community leaders, and to organize themselves within local governance frameworks. Extended family is a proven effective and supportive social protection system and safety net in rural communities, which are largely homogenous with a traditional chief that provides guidance and leadership in matters affecting the community.

Urbanization has resulted in the dual challenge of increased social and environmental turbulence and the urgency of meeting development needs whilst improving human wellbeing. The large concentration of people and assets in urban areas has increased the impact of natural hazards. The exposure of vulnerable and excluded communities residing in both areas of formal and informal land tenure to natural and human-made hazards is high, and for some communities, such as those in informal and squatter settlements, vulnerability is exacerbated by social and economic inequities.

Social protection in the Pacific derives from the role of family and self-provision and traditional forms of 'collectivity' within families. In Melanesia, for example, this extended network and emphasis on reciprocity is reinforced by reliance on wantok (clan members). Across the Pacific, such traditions involve social and economic obligations and in many cases are linked to communal land tenure. However, in the new urbanizing settings, these traditional social networks are showing signs of strain [8].

Countries such as Vanuatu, Fiji, Samoa, and Solomon Islands have increasingly recognized the need to integrate resilience as a core strategy of development actions across multiple sectors, scales and regions. This recognition reflects awareness of the fundamental importance of the environment to human wellbeing and the integrative effect of culture on development initiatives. Whilst there are strong arguments for cultural resilience and populations retaining traditional knowledge (including experience of adverse weather), second and third generation urbanites are losing this knowledge and with it the ability to withstand and recover from natural hazard shocks.

\subsection{Tenure Security}

When addressing urbanization, disaster risk and longer-term climate change adaptation in PICs, land tenure is a critical consideration as there are important linkages at the settlement level between tenure security, perception of vulnerability, and people's ability to adapt [18]. In a study on five informal 
settlements in the Lami area in Fiji for example, there was a significant negative correlation $(p<0.05)$ between perceived vulnerability to both flooding and sea-level rise, and the household perception of security of tenure [19]. Often the most disadvantaged and vulnerable people face the greatest impact and have the least resources to cope with and recover from disasters. The tension between the formal tenure categories in urban areas (freehold and State land), and the often predominantly customary ownership of land in peri-urban areas, is a significant challenge [2,6].

As informal and squatter settlements develop in Pacific urban areas, settlers increasingly occupy traditional or customary lands in peri-urban areas. However, at local scales the underlying tenures are diverse and strongly influence the complexity of the land tenure and property rights negotiated between settlers and landowners [13]. This can include informal settlers occupying religious, State or freehold lands, quasi-renting agreements, informal 'ownership', or occupation of customary lands. Settlements can occur on State and customary lands through settlers claiming land rights by occupation. In most cases, occupation does not involve a payment by settlers occupying state lands, unless an arrangement is formalized via temporary or permanent leases [13]. Numbasa and Koczberski [20] found in Wewak in PNG, for example, that an informal land market had developed characterised by informal tenure arrangements between migrant settlers and customary landowners or people with traditional relationships, marriage or friendship ties with the landowning group. This is also a situation found in informal settlements on customary land in Greater Suva and Lautoka in Fiji [21].

Settlers negotiate informal land tenure and property rights with the customary landowner that includes buying the land and associated land rights according to customs [22,23]. These customary agreements may be enshrined in formal legal statutes or may, in some cases, be illegal under the formal system. Those developed via customary practices are generally more socially legitimate and come with greater perceived tenure security, as in the vakavanua process of obtaining permission from landowning groups in Fiji [24]. However, as Bryant-Tokalau [25] notes, these agreements may change as circumstances evolve. Tenure can be made more secure by cash and in-kind contributions, formal or informal record keeping, underpinned by a set of rules acceptable to landowning group and the settlers [26].

Informal and squatter settlements in the peri-urban areas of PIC urban areas, however, do not necessarily have insecure land tenure. In a study of informal settlements in Lami in Fiji and Wewak in PNG household perceptions of the threat of eviction were generally 'not-vulnerable' to 'vulnerable' in Lami, and ranged from 'not-vulnerable' to 'very vulnerable' in Wewak. Key factors in the perception of tenure security appeared to be the underlying tenure arrangements, the way land was accessed, and the quality of relationships with key stakeholders [27]. It is increasingly acknowledged that there exists a continuum of levels of tenure security of use and development rights enshrined in tenure arrangements $[14,28,29]$, and this certainly is the case in PICs. The permanency of security of land tenure in PIC settlements is impacted by a number of factors including political allegiance, social cohesion within settlements, the means of access, length of occupation, and the extent of buildings and community infrastructure developed $[13,30]$. Ultimately, the perception by settlers of their security of land tenure, including risk of eviction, constraints on their liveability and other tensions that may arise, can be one of the indicators of the resilience of local communities.

\subsection{Natural Environment and Socio-Ecological Relationships}

In addition to being valuable habitats that house distinctive local flora and fauna, the natural environment also acts as a critical source of food, water, and raw materials for PIC communities. In addition, the natural environment provides broader benefits-provisioning, regulating, supporting and cultural—that are collectively understood as 'ecosystem services' [31]. In the cultural case, the local environment holds considerable social and cultural significance for PIC communities as evidenced through a range of services such as ceremonies, art, tourism, and recreation.

PICs have traditionally relied on locally-sourced food from land, lagoon, and marine environments for both subsidence and cash income. Indeed, many urban communities continue to rely on 
'bush gardens' in the peri-urban areas to grow their vegetables and utilize forests as a valuable source of fruit, nuts, and medicines, as well as firewood, timber for construction, and raw material for handicrafts. Lagoons and marine environments are also home to a variety of fish and shellfish which are a primary source of food for many communities in the Pacific.

However, the continued integrity and healthy functioning of local ecosystems and the benefits derived from their services are being increasingly impacted by a combination of urbanization and climate change. Urbanization is not only leading to a direct loss of the natural environment, but is also increasing the risk of urban floods and erosion, with the pollution arising from human activity a major problem as towns and cities in the Pacific expand rapidly. This is evidenced not only in the generation and adequate disposal of solid waste, but problems also arise as a result of a lack of universal access to sanitation and toilet facilities. Continued access to clean water is perhaps one of the most critical issues for PICs-with water quality and supply threatened by human-derived pollution (as settlements impinge on water boreholes, wells, or pollute nearby watercourses) and climate change (a rise in sea level increasing the risk of salinization of groundwater resources for local and public water supply purposes).

\subsection{Economic}

Collectively PICs reflect a diversity of land areas and types, population size, culture, kin and ethnic composition, and economic opportunities. Despite this diversity, many PICs share common challenges, such as geographic isolation, vulnerability to natural disasters and climate change, and limited natural resources. All of these constrain their economic development potential. Additionally, human, technical, institutional, and sociocultural constraints also impact on the ability of PICs to effectively manage their economies including the sharing of social, economic and environmental benefits for all of the populations, both urban and rural [13].

Despite their relative smallness, Pacific urban areas play pivotal roles as engines of growth, both nationally and regionally. Whilst not well recognized as major contributors of GDP, Pacific urban areas remain influential as centers for both formal and informal activity playing a major role in supporting and facilitating non-urban-based economic activities such as mining, fishing, and forestry. Pacific urban areas are also centers of national and regional service facilities such as health care, schools, and tertiary education. However, the potential contribution of urban areas to economic and social growth is constrained by the remoteness of many PICs (and their outer islands), plus inadequate infrastructure and services in terms of coverage, adequacy of service levels, and quality. There is also an inability to access urban land in a timely and 'secure' manner for planned urban development, plus there are high costs of housing and rising urban security concerns. Collectively, these place constraints on the economic development potential of many PICs for local and international investors. The most vulnerable, particularly small atoll states, are further constrained by size, physical isolation, and limited natural resources.

\section{The Global ‘New Urban Agenda'}

In October 2016, in Quito, Ecuador, the international community adopted the New Urban Agenda which aims to reinvigorate political commitment for the three traditional pillars of sustainable development: social inclusion and ending poverty (social), inclusive urban prosperity and opportunities for all (economic), and environmentally sustainable and resilient urban development (environment). The New Urban Agenda also places greater emphasis on creating situations that 'enable' implementation, the emerging role of new governance structures (stressing the importance of city authorities as being part of the solution), participatory planning, and equity and gender considerations [32].

The ambitious commitments draw close parallels to the 2015 Pacific Urban Agenda priorities as well as the national sustainable development priorities embedded in Goal 11 of the Sustainable Development Goals ('make cities and human settlements inclusive, safe, resilient and sustainable'). 
The Pacific Urban Agenda and the New Urban Agenda share the commonality of being non-binding agreements, with the additional value of regional and international visibility and the potential political momentum that they create. This includes exerting pressure on governments to fulfill their responsibility for sustainable urban development, and galvanizing community based entities such as NGOs in pursuing specific urban-based outcomes.

Perhaps of greatest relevance to PICs are the New Urban Agenda's points on climate change and resilience-factors that feature highly on national and international development agendas and priority commitments. In terms of land governance, the New Urban Agenda commits to promote increased security of land tenure for all and addressing the associated complexities of land management and administration in urban and peri-urban environments [32] (p. 8). The Habitat III Pacific Region report also noted that land tenure is a critical issue for the Pacific [2]. However, the Pacific Urban Agenda does not directly highlight improved land tenure security—but rather, refers to improving institutional structures for better management of urban growth and the provision of basic services as a means to addressing land challenges in an urban-rural setting. Both agendas have a complementary vision for provoking more inclusive action in urban areas by increasing engagement of, and cooperation with, the private sector, civil society, and improving recognition of the role of local government. Furthermore, both agendas aim to shape an urban development future that reaps the benefits of economic opportunities, protects the environment, and promotes 'cities for people'.

The New Urban Agenda calls for an integrated approach across multiple sectors, which the PICs recognize, but they face the challenge of implementing sustainable solutions. The visionary language is inspiring, but the pragmatism is lacking within a framework that assumes an understanding of urbanization as a linear process and the required positioning that harnesses the opportunities that urban development and investment may bring. International and regional agendas are valuable in assisting PICs to articulate relevant goals, but without any practical implementation advice and financial and technical resources to support implementation of actions to realize the vision, both national and Pacific urban agendas will continue to struggle with elevating sustainable urban management as a priority. In other words, it will have little traction at the city and local levels unless integrated into wider-and implementable—visions and plans.

\section{Challenges and Opportunities in Implementing the Pacific Urban Agenda}

\subsection{Urban Spatial Planning}

Central to implementing the recommendations of the Pacific Urban Agenda at the national level is the role of urban spatial planning. Urban spatial planning facilitates basic urban service and infrastructure provision and, importantly, reflects the vision of city stakeholders as to the town/city they want. However, the position of spatial planning in urban and national development agendas remains problematic - a key symptom being its non-alignment and non-inclusion with economic and investment plans [13]. It has been acknowledged that implementation resources, including coordination amongst regional stakeholders to address Pacific Urban Agenda priorities such as land and housing, have not been consistent in the urban sector due to a lack of human and technical capacity, varying political momentum and inertia and an absence of development partner commitment $[8,33]$. As reflected at the Pacific regional level, there remains a lack of ongoing support for integrating urban issues into projects that can be scaled up for implementation at the city level. There are a number of underlying reasons for this:

- Pacific urban management and development is multi-sector requiring diverse stakeholders and urban policy agendas to work together. Additionally, urban planning issues must be weighed up against competing concerns in rural areas as this is where the bulk of PIC populations still reside. This provides a dilemma for elevating urban planning into the wider Pacific development debate including articulating what a sustainable 'urban governance framework' incorporating urban spatial planning may look like. 
- The benefits of improved urban spatial planning and management still remain poorly articulated by policy makers. The reality is many national economic planners do not see 'urban' as a sectoral development theme with spatial implications, meaning that not all urban residents are being included and allowed access to the benefits of urbanization.

- National political champions who understand the complexities of urban issues and urbanization process and take a longer-term perspective are few. Many urban politicians are cautious as planning and the development of urban projects invariably involves confronting complex landownership issues, including liaising with customary landowners.

- With increasing urban populations in informal and squatter settlements, the priorities for many households relate to day-to-day survival, rather than medium to longer-term projects generated by—sometimes alien—forms of urban spatial planning.

The collective result of the above is that developing and implementing consistent urban policies and plans at both national and regional levels-as is needed in the implementation of the Pacific Urban Agenda-remains challenging. Ongoing urban spatial planning requires a far greater emphasis on contextual solutions underpinned by strong local community support and political commitment at a range of levels. This requires new ways of developing and implementing projects, including a greater understanding of local conditions using the traditional knowledge of existing communities, and longer and more realistic timeframes.

\subsection{Responsible Urban Land Governance}

The New Urban Agenda commits to promoting secure land tenure for all to support sustainable and inclusive urban economies [32]. Effective and responsible urban land governance is also at the core of progressing the Pacific Urban Agenda. As the Pacific report informing Habitat III notes, the way the transition from informal occupancy of land to 'formal settlement' takes place "will have a major influence on the future 'health' of Pacific cities and their inhabitants" [2] (p. 5).

At the core of responsible land governance is recognizing, recording and respecting all legitimate rights to land [34]. In the Pacific Islands context, this typically will require assessing existing rights to land and their perceived security of tenure. This information can inform vulnerability assessments, action plans, and settlement upgrading initiatives. Approaches that seek to upgrade informal and squatter settlements or improve tenure security should favor simple, affordable, and appropriate methods to improve tenure security. The focus in both the Pacific Urban Agenda and the New Urban Agenda on the continuum of land and property rights and recognition of the plurality of tenure types is especially welcome and important for PICs.

Responsible urban land governance can help to advance the four key recommendations of the Pacific Urban Agenda through:

- Social equity: housing and settlement upgrading projects can provide options for improved access to serviced land, and more secure land tenure and property rights. Community based rights can be established using participatory methods that involve recording land rights through community enumeration [35]. UN-Habitat participatory slum upgrading programs active in PNG, Fiji, and Solomon Islands typically incorporate this approach. Corresponding action plans can include fit-for-purpose approaches for improving tenure security and recognizing land rights, in line with urban planning and management.

- Environment, resilience and urbanization: ensure urban resilience is more comprehensively addressed through integrating perceptions of tenure security and land conflicts into vulnerability assessments and embedding principles of responsible land governance into the development of national urban or urbanization policies. Promoting increased security of tenure will require recognition of the continuum of land and property rights, and the development of fit-for-purpose, and age-, gender-, and environment-responsive land administrative systems [32]. 
- The urban economy: protecting legitimate land rights and developing effective systems for the valuation of all land tenures supports stronger land markets and urban economies.

- Urban governance frameworks strengthened: whether constituted in the formal or informal realms, recording and valuing legitimate land rights provides a basis for improved land-based financing to enhance municipal income streams.

A challenge moving forward will be how to improve tenure security across the full range of land tenures that exist in PICs at scale, including third-party rights such as rental agreements, and for all people. Critically, efforts to improve urban land governance need to be mindful of the complexity of addressing land issues in PICs. Land tenure systems, especially those based on custom are extremely complex, and an assessment of the land tenure issues and perceptions of tenure security, and options for improving tenure security, should inform all decisions.

\subsection{Partnerships and Enabling Networks}

The Pacific has a well-established regional structure supported by national governments and a number of economic and technical support agencies that collectively interact to achieve a variety of shared development goals, regional projects, and policy initiatives. The 2007 Pacific Urban Agenda, for example, was included in the Pacific Plan for Strengthening Regional Cooperation and Integration (active from 2005-2014). The Pacific Urban Agenda has had some successes as an advocacy platform, but has been less successful in its implementation—hindered by limited technical and human resources and a lack of multi-partner commitment. Without regional support, this has resulted in caution by both governments and leaders in evaluating the social, economic, environmental and political implications of urban change, rather than a conscious decision not to address urban issues.

Few PICs have experienced successes with national urban networks. PICs require committed and active leadership, and champions, along with well-articulated, resourced and integrated plans for urban development. Such plans and strategies need to be developed through effective community consultations and then strong partnerships between national and local governments, public corporations (as service providers), traditional leaders and landowners, community-based organisations, the private sector, and development partners. These partnerships are important in addressing potential threats that undermine living standards, sustainability and economic growth, and in creating healthy and safe living environments across urban and peri-urban areas. That is no small challenge, and hence the notion of finding acceptable entry points into enhancing and promoting Pacific urban management has been used [13,36].

The relatively weak capacity in many PICs means that effective financial and technical support of international bilateral and multilateral organisations and professional bodies will be required, as well as coordination and harmonization between international and national stakeholders in order to achieve multi-stakeholder, multi-actor and multi-sectorial solutions at regional or national levels [37].

\subsection{Integrated Urban Resilience Action Plans}

Urban resilience promotes an integrated consideration of multiple shocks and stresses that act on the urban system both now and into the future. This paper has argued that such a holistic approach is critical in the Pacific; a complex regional landscape where multiple drivers impact on the unique social, cultural, economic, environmental, and governance dimensions of urban areas. The need for integrated action in the region has also been recently recognized by the 'Framework for Resilient Development in the Pacific 2017-2030' [38]. This new voluntary initiative has brought together the two previously separate regional frameworks for climate change and disaster risk management (which expired in 2015) and provides guidance on how to enhance resilience to climate change and disasters in ways that contribute to, and are embedded in, sustainable development.

The value of resilience thinking was reinforced by the experience and learning that was experienced by the project team during the application of the UN-Habitat 'Planning for Climate 
Change' framework (PfCC) in Port Vila and Honiara between 2014 and 2017. The original intention was to use a range of participatory approaches to develop local climate change adaptation plans for both cities based on climate vulnerability assessments $[39,40]$ that were underpinned by the 'Pacific Climate Futures' scenarios produced by the Pacific-Australia Climate Change Science Adaptation Planning program. However, as became evident during engagement with local stakeholders, existing exposure to climate variability (cyclones and floods) and natural hazard extreme events (earthquakes and tsunamis) meant that disaster risk reduction (DRR) principles also needed to be factored into the development of local action plans (considering the impacts of current-day shocks as well as longer-term stresses). Furthermore, discussions with communities highlighted that they are served by inadequate infrastructure, services and housing stock, are under considerable population and urbanization pressures, and lack the institutional capacity at the community and municipal level to effectively respond to urbanization and global environmental change. All are characteristics that heighten sensitivity to climate-related shocks.

The range of different issues and concerns that were elicited from local communities illustrated the need for a broader resilience approach-one that integrated DRR (current-day climate and non-climate shocks), climate change adaptation (longer term shocks and stresses) and development agendas (changing societal exposure and sensitivity to the hazards). Even though it was recognized that the impacts of future climate change are important and needed to be explicitly considered, climate change is only one of multiple drivers with the potential to undermine the resilience of the major Pacific cities and there are many more immediate needs that require action in order to provide an initial platform for climate adaptation planning and sustainable urban development. This is illustrated by the graphical representation of priority community resilience issues that were identified by informal settlers in Honiara (Figure 1). These findings provide stark evidence of the over-riding emphasis to address short-term development needs (sanitation, overcrowding, waste management etc.) as a precursor to climate resilience (the main priorities being flooding and water security), and were a key influence in extending the climate change remit to 'urban resilience and climate actions plans' for both Honiara [10] and Port Vila (forthcoming, 2017).

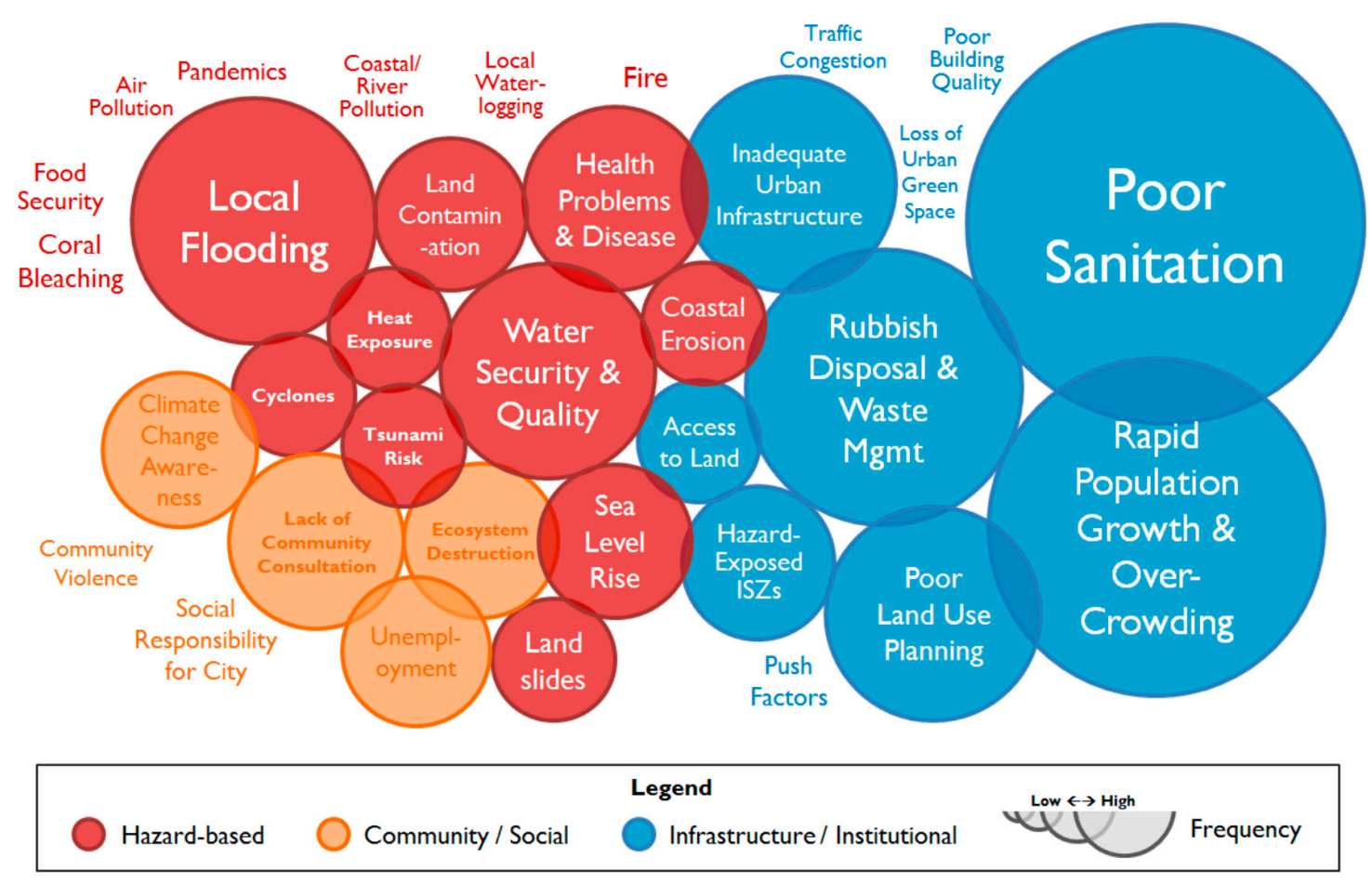

Figure 1. Community-level priority issues in Honiara [10]. 


\section{Concluding Discussion}

PICs are rapidly urbanizing, but effective management of this transformation is limited. The growth of squatter and informal settlements-particularly in the urban areas of Melanesia-is a clear manifestation of continued, largely unmanaged, urbanization. The Pacific is impacted by a range of natural hazards, some increasing in frequency and intensity. In addition, large proportions of Pacific urban areas are highly exposed to natural hazards given their particular location such as coastal hinterlands. Combined with poor housing quality and deficits in critical services and infrastructure, sensitivity is high. Adaptive capacity is also constrained by weaknesses in governance, land-use planning, lack of public finances, and the complexities of dual formal/customary land tenure and wider informality systems intersecting to varying degrees.

In the above setting, the management of Pacific urbanization remains problematic. Regional efforts to create traction with urban management-such as the Pacific Urban Agenda-have struggled to galvanize attention, resourcing, and advancement. It remains to be seen if the recently adopted global New Urban Agenda will be effective as a top down mechanism to promote visibility and create political momentum in a region of small island states unique in their development needs. Nevertheless, enhanced urban management is critical in creating better social, economic, and environmental urban outcomes for PICs. Furthermore, improvements in issues of equality (addressing the informal status of many urban dwellers for example), gender considerations, and the inclusion of youth would all make valuable contributions to sustainability solutions, emphasizing the need for greater inclusion in the design of policies and actions for urban resilience and sustainability in the Pacific.

An urban resilience lens offers a useful framework for understanding urban challenges and for identifying possible opportunities and solutions particularly in a region used to shocks and stresses. However, the challenge of implementation remains. As this paper has discussed, a resilience lens showcases that adequately managing ongoing urbanization and adapting to changing climate patterns requires effective urban spatial planning, responsible urban land governance, enabling partnerships, and comprehensive urban resilience action plans. In a unique region, approaches based on one-size-fits-all will not work. Rather, what is needed is a balance between top down and bottom up approaches that build from existing community structures and their guiding governance frameworks. The future of the Pacific is clearly predominantly urban and, as such, effective urban management using contextualized approaches that understand, work with, and enhance the resilience of urban areas are more urgent than ever.

Acknowledgments: This paper is based on a variety of recent and ongoing projects in the region, including funders such as UN-Habitat, Global Land Tool Network, Royal Institution of Chartered Surveyors, SPREP, UNESCAP and the Asian Development Bank.

Author Contributions: Each author contributed to the paper by drawing on their particular research project experience in the Pacific region.

Conflicts of Interest: The authors declare no conflicts of interest.

\section{References}

1. UN-Habitat and Commonwealth Local Government Forum (CLGF). Pacific Urban Forum 2015: Towards a New Urban Agenda. Harnessing Opportunities in a Post-2015 Environment. Available online: http:/ / www.clgfpacific.org/userfiles/3/file/2015\%20Pacific\%20Urban\%20Forum\%20Resolution\% 20and\%20Outcomes\%20Document.pdf (accessed on 17 October 2017).

2. UN-Habitat. Habitat III Report: The Pacific Region; Draft; UN-Habitat: Fukuoka, Japan, 2015.

3. United Nations Department of Economic and Social Affairs. World Urbanization Prospects: The 2014 Revision. Available online: https:/ / esa.un.org/unpd/wup/publications/files/wup2014-highlights.Pdf (accessed on 17 October 2017).

4. Keen, M.; Barbara, J. Pacific Urbanization: Changing Times, State, Society and Governance in Melanesia. Available online: http://ips.cap.anu.edu.au/sites/default/files/IB-2015-64-Keen\%2BBarbara.pdf (accessed on 17 October 2017). 
5. Reckien, D.; Creutzig, F.; Fernandez, B.; Lwasa, S.; Tovar-Restrepo, M.; McEvoy, D.; Satterthwaite, D. Climate change, equity, and sustainable development goals: An urban perspective. Environ. Urban. 2017, 29, 159-182. [CrossRef]

6. Mitchell, D.; Jacot des Combes, H.; Myers, M.; McEvoy, D. Addressing land issues in disaster risk management in the Pacific island countries. Land Tenure J. 2014, 1, 105-135.

7. Jones, P. Constraints and Opportunities to Implementing the Pacific Urban Agenda; UN-Habitat: Fukuoka, Japan, 2011.

8. Jones, P. The emergence of Pacific Urban Villages: Urbanisation Trends in the Pacific Islands. Available online: https:/ / www.adb.org/sites/default/files/publication/201291/pacific-urban-villages.pdf (accessed on 17 October 2017).

9. World Bank. Unsettled: Water and Sanitation in Urban Settlement Communities of the Pacific. Available online: http:/ / reliefweb.int/sites/reliefweb.int/files/resources/127-Unsettled\%20-\%20Water\% 20Sanitation\%20in\%20Urban\%20Settlements\%20in\%20the\%20Pacific.pdf (accessed on 17 October 2017).

10. Alexei, T. Honiara Urban Resilience and Climate Action Plan; UN-Habitat: Fukuoka, Japan, 2017.

11. Conroy, J. Papua New Guinea: Policy for the Informal Economy. Available online: http:/ / devpolicy.org/ papua-new-guinea-policy-for-the-informal-economy20110519/ (accessed on 17 October 2017).

12. UN-Habitat and UNESCAP. State of Asian and Pacific Cities 2015: Urban Transformations Shifting from Quantity to Quality. Available online: http:/ / www.unescap.org/sites/default/files/The\%20State\%20of\% 20Asian\%20and\%20Pacific\%20Cities\%202015.pdf (accessed on 17 October 2017).

13. Jones, P. The State of Pacific Towns and Cities: Urbanisation in ADB's Pacific Developing Member Countries; Pacific Studies Series: Mandaluyong, Philippines, 2012.

14. Payne, G.; Piaskowy, A.; Kuritz, L. Land Tenure in Urban Environments. Available online: https://www. land-links.org/issue-brief/land-tenure-in-urban-environments/ (accessed on 17 October 2017).

15. Phillips, T.; Keen, M. Sharing the City: Urban Growth and Governance in Suva. Available online: http://ssgm.bellschool.anu.edu.au/sites/default/files/publications/attachments/2016-09/dp_2016_6_ phillips_and_keen.pdf (accessed on 17 October 2017).

16. May, R. Review of the Historical Context of Current Land Management and Conflict Management Situations in the Pacific. Available online: http:/ / citeseerx.ist.psu.edu/viewdoc/download?doi=10.1.1.465.3224\&rep= rep1\&type $=$ pdf (accessed on 17 October 2017).

17. Australian Bureau of Meteorology. Climate in the Pacific: A Regional Summary of New Science and Management Tools. Available online: http://www.pacificclimatechangescience.org/wp-content/uploads / 2013/06/Climate-in-the-Pacific-summary-48pp_WEB.pdf (accessed on 17 October 2017).

18. Reale, A.; Handmer, J. Land tenure, disasters and vulnerability. Disasters 2011, 35, 160-182. [CrossRef] [PubMed]

19. Orcherton, D.; Mitchell, D.; McEvoy, D. Perceptions of Climate Vulnerability, Tenure Security and Resettlement Priorities: Insights from Lami Town, Fiji Islands. Aust. Geogr. 2016, 48, 1-20. [CrossRef]

20. Numbasa, G.; Koczberski, G. Migration, informal urban settlements and non-market land transactions: A case study of Wewak, East Sepik Province, Papua New Guinea. Aust. Geogr. 2012, 43, 143-161. [CrossRef]

21. Kiddle, G.L. Perceived security of tenure and housing consolidation in informal settlements: Case studies from urban Fiji. Econ. Bull. 2010, 25, 193-214.

22. Chand, S.; Yala, C. Improving Access to Land within the Settlements of Port Moresby; National Research Institute: Port Moresby, Papua New Guinea, 2008.

23. Monson, R. Women, State Law and Land in Peri-Urban Settlements on Guadalcanal, Solomon Islands; World Bank: Washington, DC, USA, 2010.

24. Kiddle, G.L. Vakavanua Settlements in Fiji; Just Change: Wellington, New Zealand, 2009.

25. Bryant-Tokalau, J. Living in the Qoliqoli: Urban squatting on the Fiji foreshore. Pac. Stud. 2010, 33, 1-20.

26. Chand, S.; Yala, C. Institutions for improving access to land for settler-housing: Evidence from Papua New Guinea. Land Use Policy 2012, 29, 143-153. [CrossRef]

27. Mitchell, D.; Orcherton, D.; McEvoy, D. The Implications of Land Issues for Climate Resilient Informal Settlements in Fiji and Papua New Guinea; Royal Institute of Chartered Surveyors: London, UK, 2016.

28. Barry, M. Property Theory, Metaphors and the Continuum of Land Rights; Global Land Tool Network, UN-Habitat: Fukuoka, Japan, 2015. 
29. Sietchiping, R.; Aubrey, D.; Bazoglu, N.; Augustinus, C.; Mboup, G. Monitoring Tenure Security within the Continuum of Land Rights: Methods and Practices. Available online: http:/ / www.landandpoverty.com/ agenda/pdfs/paper/sietchiping_full_paper.pdf (accessed on 17 October 2017).

30. Chand, S.; Yala, C. Informal land systems within urban settlements in Honiara and Port Moresby. In Making Land Work (2): Case Studies on Customary Land and Development in the Pacific; Australian Agency for International Development: Canberra, Australia, 2008.

31. Millennium Ecosystem Assessment. Ecosystems and Human Well-Being: A Framework for Assessment. Available online: http:/ / millenniumassessment.org/en/Framework.html (accessed on 17 October 2017).

32. United Nations General Assembly. Resolution Adopted by the General Assembly on 23 December 2016: New Urban Agenda. Available online: http:/ / habitat3.org/wp-content/uploads/New-Urban-Agenda-GAAdopted-68th-Plenary-N1646655-E.pdf (accessed on 17 October 2017).

33. Mecartney, S. An Urban Pacific-The Challenge of Managing Change; University of Sydney: Sydney, Australia, 2014.

34. Committee on World Food Security and Food and Agriculture Organization. Voluntary Guidelines on the Responsible Governance of Tenure of Land, Fisheries and Forests in the Context of National Food Security. Available online: http:/ / www.fao.org/docrep/016/i2801e/i2801e.pdf (accessed on 17 October 2017).

35. UN-Habitat. Count Me in, Surveying for Tenure Security and Urban Land Management; UN-HABITAT: Nairobi, Kenya, 2010.

36. Mecartney, S.; Connell, J. Urban Melanesia: The challenges of managing land, modernity and tradition. In Kastom, Property and Ideology: Land Transformations in Melanesia; McDonnell, S., Allen, M.G., Eds.; ANU Press: Canberra, Australia, 2017; pp. 57-84.

37. International Federation of Surveyors (FIG). FIG Christchurch Declaration: Responding to Climate Change and Tenure Insecurity in Small Island Developing States-The Role of Land Professionals. Available online: http:/ / www.fig.net/resources / publications / figpub / pub68/Figpub68.pdf (accessed on 17 October 2017).

38. The Pacific Community. Framework for Resilient Development in the Pacific: An Integrated Approach to Address Climate Change and Disaster Risk Management. Available online: http:/ / www.pacificdisaster.net/ dox/FRDP_2016_Resilient_Dev_pacific.pdf (accessed on 17 October 2017).

39. UN-Habitat. Climate Change Vulnerability Assessment, Honiara, Solomon Islands; UN-Habitat: Fukuoka, Japan, 2014.

40. UN-Habitat. Climate Change Vulnerability Assessment, Port Vila, Vanuatu; UN-Habitat: Fukuoka, Japan, 2015. 